\title{
A new model for estimating district life expectancy at birth in India, with special reference to Assam state
}

\author{
Rajan Sarma ${ }^{1}$ \\ Labananda Choudhury
}

\begin{abstract}
Life expectancy at birth $\left(e_{0}\right)$ is considered as an important indicator of the mortality level of a population. In India, direct estimation of $e_{0}$ is not possible due to incomplete death registration. The Sample Registration System (SRS) of India provides information on $e_{0}$ only for the 16 major states. Estimates of $e_{0}$ for the districts are not available. Using data from the Coale-Demeny West model life tables, United Nations South Asian model life tables, and SRS life tables of India and its major states, the paper shows that the relationship between life expectancy at age one $\left(e_{1}\right)$ and the probability of surviving to age one $\left(l_{1}\right)$ is linear, and the relationship between $e_{0}$ and $l_{1}$ is quadratic. From the quadratic relationship between $e_{0}$ and $l_{1}$, an attempt is made to estimate $e_{0}$ for some selected districts of India for 2001 and 2010, using estimated $l_{1}$ from 2001 census data and Annual Health Survey (2010-11) data.
\end{abstract}

Keywords: district, India, life expectancy at birth, regression.

\section{Résumé}

L'espérance de vie à la naissance $\left(e_{0}\right)$ est considérée comme un indicateur important du niveau de mortalité de la population. En Inde, il est cependant impossible de donner une estimation d' $e_{0}$ en raison du fait que le registre des décès est incomplet. Le système d'enregistrement (Sample Registration System [SRS]) de l'Inde fournit de l'information sur $e_{0}$ seulement pour les 16 États les plus importants. Les estimations pour les districts ne sont pas disponibles. À partir des tableaux du modèle de Coale et de Demeny (Coale-Demeny West life tables), des tableaux de l'Asie du Sud-Est des Nations Unies et des tableaux SRS de l'Inde et de ses principaux États, cet article démontre que la relation entre l'espérance de vie à l'âge de un an $\left(e_{1}\right)$ et la probabilité de survivre jusqu'à l'âge de un an $\left(l_{1}\right)$ est linéaire et que la relation entre $e_{0}$ et $l_{1}$ est quadratique. On a tenté, à partir de la relation quadratique $\mathrm{d} e_{1}$ et $\mathrm{de} l_{1}$, d'estimer $e_{0}$ pour certains districts de l'Inde pour 2001 et 2010 en utilisant les données estimatives $l_{1}$ du recensement de 2001 et du sondage annuel sur la vie (Annual Health Survey) de 2010-2011.

Mots-clés : district, espérance de vie à la naissance, Inde, régression.

1. Rajan Sarma, Department of Statistics, Darrang College, Tezpur-784001, Assam, India.

Email: srmrjn@gmail.com; and Labananda Choudhury, Department of Statistics, Gauhati University, Guwahati-781014, Assam, India. 
Sarma and Choudhury: A new model for estimating district life expectancy at birth in India (Assam state)

\section{Introduction}

Life expectancy at age $x\left(e_{x}\right)$ is the average number of additional years to be lived by a member of the cohort who survives to age $x$. If we know nothing else about an individual except the fact that he or she survived to age $x$, life expectancy at age $x$ would be our best guess about how long that individual would live (Preston et al. 2003). Period life expectancy at birth $\left[e_{0}(t)\right]$ is the average number of years a randomly chosen newborn in a population would live, given a set of death rates during a given time period, and has been the single most used demographic measure to describe population health (Romo and Becker 2011). The conventional way of obtaining life expectancy is through construction of a life table, which has rigorous data requirements. Life tables provide models that assess the effects of age-specific mortality rates (Pathak and Singh 1992). Construction of a life table requires information on age-specific deaths and population age distribution. Unfortunately in India the registration of deaths is not satisfactory, and this procedure cannot be adopted (Malaker 1986; Bhat 1987). On the other hand, the Sample Registration System (SRS) is the most regular source of demographic statistics in India. It is based on a system of dual recording of births and deaths, in fairly representative sample units spread all over the country. The SRS provides annual estimates of (a) population composition, (b) fertility, (c) mortality, and (d) medical attention at the time of birth or death. SRS estimates are generally valid and reliable for the country as a whole, and for the bigger states with populations of more than 10 million. Recently the sample size of the SRS has been increased to allow for estimates by natural divisions within the bigger states. Evaluations during 1970s and 1980s showed that completeness of recording of births and deaths by the SRS was generally good, and errors in recording these events were minimal. However, systematic evaluation of the SRS has not been taken up for quite some time (Mahapatra 2010). The SRS provides life tables for India and its major states, on the basis of sex and residence. Consequently, estimates of $e_{0}$ are available only for the major states (on the basis of sex and residence). However, life expectancy at sub state level has its unique importance being a potential indicator for health planning which is generally accomplished at sub state level (Wennberg and Gittelsohn 1975, 1980; Feinlieb 1984). Also, national and state level life expectancy values may not be uniformly applicable at the sub-state level, and there may be unsuspected life expectancy differentials across various districts of a state (Swanson and Stockwell 1986).

Like the United States, India has a federal political structure, while health is a state-level matter, which means that the amount and allocation of health expenditures are decided in each state individually (Bhalotra 2007). Districts are units at the next level in the administrative hierarchy under the states, and the Government of India and the state governments monitor the progress of implementation of most of the district-level development activities. Information on district-level life expectancy at birth may be helpful to the state health departments in building necessary infrastructure and obtaining the required human resources at the district level.

In the absence of age distribution of deaths, construction of life tables is possible by census age distribution at one or two points of time. But this method requires the assumption of a constant number of annual births and deaths in the recent past, and also requires the population to be closed to migration (Arriaga 1968; United Nations 1983). In India, from the rate of growth of population from censuses at different periods at national, state, and district levels, constancy of births and deaths can be ruled out. Also, as per the 2001 census, about 307 million people were reported as migrants by place of birth. Of these, about 259 million (84.2\%), migrated from one village or town to another village or town, and 42 million ( $2 \%$ ) migrated from outside the country. Data on migration by last residence in India as per the 2001 Census show that the total number of migrants was 314 million. 
Out of these migrants by last residence, 268 million (85\%) were intra-state migrants, those who migrated from one area of the state to another area; 41 million $(13 \%)$ were interstate migrants and 5.1 million $(1.6 \%)$ migrated from outside the country. ${ }^{2}$ Therefore, the construction of life tables by census age distribution is not feasible in India.

Nevertheless, several indirect methods for estimating the expectation of life at birth are available. These methods are based on (i) Stable population concept, (ii) Biological theories of ageing, (iii) Age distribution of population, (iv) Widowhood status, and (v) Regression approach (Mazur 1969a, 1969b, 1972; Carrier and Hobcraft 1971; Swanson and Palmore 1976; McCann 1976; Hill 1977; Hill and Trussell 1977; Swanson et al. 1977; Siler 1979; Gunasekaran et al. 1981; Coale and Demeny 1983; United Nations 1983; Preston and Bennett 1983; Malaker and Crook 1989; Swanson 1989). Of these methods, the regression method is perhaps the most suitable to estimate life expectancy at birth at the sub-national level in India, as it requires limited data and does not need the assumptions demanded by other methods (Pathak and Singh 1992).

In the United States, Swanson (1989) constructed a regression model for estimating life expectancy using state-level data on crude death rates (CDR) and percentage of the population aged 65 years and over $[\mathrm{P}(65+)]$. Data on CDR in India were not available at the district level till a few months back. In the last part of 2011, the Registrar General of India published some mortality and fertility measures, including the Crude Death Rates and Infant Mortality Rates (IMR) for the districts of some selected states of India through the Annual Health Survey, 2010-11.

By now, it is clear that the populations of the Indian districts are (i) non-stable and (ii) not closed to migration. These two characteristics combined together prevent almost all the available indirect techniques from providing reliable mortality estimates. The only exception, possibly, being the Brass type methods of estimating child mortality from information on children ever born (CEB) and children surviving (CS), as reported by women of different age groups in censuses and surveys (Brass 1964, 1975; Sullivan 1972; Trusell 1975; Pathak et al. 1988). These methods provide estimates of $q(x)$, the probability of dying from birth to exact age $x(x=2,3,5,10,15,20)$.

In the second half of the twentieth century, in developed countries life expectancy by age became a monotonic decreasing function with increasing age. However, in the past this was not the case. In historical populations, as well as in most developing countries, high rates of infant and early childhood mortality result in lower values of life expectancy at birth than at other ages. In such populations, those surviving the hazards of early childhood have a higher life expectancy than newborns, and the highest life expectancy occurs not at birth but at a later age (Romo and Becker 2011).

By 1950, in developed countries the only remaining life expectancy higher than $e_{0}$ was $e_{1}$ (Romo and Becker 2011). However, it has been observed from the SRS-based life tables that India took more than 30 years to have highest life expectancy occur at age one. In India, till 1980 the highest life expectancy occurred at age five, and the crossover to age one took place during 1981-85, and has remained at that age to date. In the Coale and Demeny (1966) West model life tables, this shifting of highest life expectancy to age one starts at level 14 (corresponding $e_{0}=45.594$ ) and remains at this age till level 24 (corresponding $e_{0}=73.905$ ) in the case of males, and from level 14 (corresponding $e_{0}=52.5$ ) to level 23 (corresponding $e_{0}=75.0$ ) in the case of females. Beyond level 24 (for males) and level 23 (for females) the highest life expectancy shifts to birth from age one. In the United Nations Model Life Tables for developing countries (South Asian pattern, 1982), the shifting of highest life expectancy from age five to age one occurs in the life tables corresponding to $e_{0}=57.0$ (for males) and $e_{0}=59.0$ (for females). In India, SRS life tables show this shifting from 1981-85, with correspond-

2. http://censusindia.gov.in/Census_And_You/migrations.aspx 
ing $e_{0}=55.45,53.95,55.67$ for individuals, males, and females, respectively. In all the major states of India except Kerala, the shifting of highest life expectancy from age five to age one occurred during the 1980s and these states have not experienced the crossing over of highest life expectancy from age one to birth to date. In Kerala, on the other hand, the highest life expectancy occurs at birth right from the beginning, ever since the SRS life tables (1970-75).

In populations where the highest life expectancy occurs at age one, those who survive the hazards of infancy (from birth to age one) gain extra years of life expectancy on top of the year they have already lived. Thus, changes in mortality in the first year of life strongly affect life expectancy at birth.

With this background, this paper seeks to establish relationships between the probability of surviving to age one $\left(l_{1}\right)$ and life expectancy at birth $\left(e_{0}\right)$ for the major states of India. Using these relationships and the data on $l_{1}$, an attempt has been made to estimate $e_{0}$ for 2001 and 2010, for the districts of Assam and also for some selected districts of the six major states covered by the Annual Health Survey (AHS) of India, 2010-11. The district-level data on $l_{1}$ for 2001 are obtained by a method suggested by Sarma and Choudhury (2012). For 2010, the data on $l_{1}$ are taken from AHS, 2010-11.

\section{Methods and data}

Let the function describing the number of survivors at age $x$ and at time $t$ in a life table be denoted as $l(x, t)$. Life expectancy at age $x$ and at time $t$ is calculated in terms of the survival function as:

$$
e_{x}(t)=\frac{\int_{x}^{w} l(a, t) d a}{l(x, t)}
$$

where $w$ is the highest age attained by a member of the population. To simplify some of the equations presented below, let the radix of the life table be equal to one, i.e., $l(0, t)=1$.

$$
e_{0}(t)=\int_{0}^{w} l(a, t) d a=\int_{0}^{1} l(a, t) d a+\int_{1}^{w} l(a, t) d a
$$

The first term on the right is the person-years lived between birth and age one, while the second term is the product of life expectancy at age one by the number of survivors at age one:

$$
e_{0}(t)={ }_{1} L_{0}(t)+e_{1}(t) l_{1}(t)
$$

(1; Romo and Becker 2011)

where $l_{1}(t)=l(1, t)=l(0, t)-{ }_{1} d_{0}(t)=1-q(1)$, since $l(0, t)=l_{0}=1$

and $\quad q(1)={ }_{1} q_{0}(t)=\frac{{ }_{1} d_{0}(t)}{l(0, t)}={ }_{1} d_{0}(t)$

${ }_{1} L_{0}$ is generally assumed to be a weighted linear function of $l_{1}\left(_{1} L_{0}=\mathrm{a}+\mathrm{b} l_{1}\right.$; where generally, $\mathrm{a}=0.276$ and $\mathrm{b}=0.724$; Shryock and Seigel 1976). If $e_{1}$ can assumed to be a linear function of $l_{1}\left(e_{1}=c+d l_{1} ; s a y\right)$ then $e_{0}$ will be a quadratic function of $l_{1}$.

From (1), $\quad e_{0}=a+b l_{1}+\left(c+d l_{1}\right) l_{1}$; omitting $t$ for convenience,

i.e., $\quad e_{0}=a+(b+c) l_{1}+d l_{1}^{2}$ 
We have checked the life tables of the West Model (Coale and Demeny 1966), the United Nations Model for developing countries (South Asian Pattern 1982) and SRS life tables of India (1970-75 to 2001-05) for the existence of the linear relationship between $l_{1}$ and $e_{1}$ and quadratic relationship between $l_{1}$ and $e_{0}$ by the regression method of curve estimation. It has been found that the relationship between $l_{1}$ and $e_{1}$ and between $l_{1}$ and $e_{0}$ can be considered as linear and quadratic, respectively (Table 1).

From the relationship between $l_{1}$ and $e_{0}$ obtained from the SRS life tables of India, we can estimate the $e_{0}$ of the districts of different states by using the estimated $l_{1}$ of the districts. The higher the value of $l_{1}$ [or lower the value of $q(1)$ ] the higher will be the value of $e_{0}$ obtained from this estimating equation (refer to Table 1) across all districts, irrespective of the state to which they belong. However, the states in India differ in population structure, religion, culture, and racial and ethnic background. The states are also marked by a wide disparity in economic and social development. Some states are better off in terms of economic development, while others have recorded remarkable social progress. Entitlements to basic commodities and services also differ significantly among states (Das 1999). As a result, these states have unique mortality patterns. For instance, Uttar Pradesh has a higher infant mortality $[q(1)]$ than Assam, but also has a higher life expectancy at birth than Assam (Registrar General of India, SRS life tables 2001-05). Therefore, a single equation based on the life tables of India will not be appropriate for estimating $e_{0}$ of the districts of all the states. Instead, we have checked the individual SRS life tables of each of the major states for the existence of linear relationships between $l_{1}$ and $e_{1}$ and quadratic relationships between $l_{1}$ and $e_{0}$.

It has been observed from the SRS life tables of the major states that the relationship between $e_{1}$ and $l_{1}$ is approximately linear (Table 2 ), and therefore the relationship between $e_{0}$ and $l_{1}$ is quadratic. We have derived quadratic equations from the SRS-based life tables of the major states (covering a period of 30 years, from 1970-75 to 2001-05), taking $l_{1}$ as an independent variable and $e_{0}$ as an dependent variable. Districts of the same state with a higher $l_{1}$ will, of course, have a higher $e_{0}$, but

Table 1. Relationships between $l_{1}$ and $e_{1}$ and $l_{1}$ and $e_{0}$ by the regression method of curve estimation for life table of West Model, United Nations South Asian pattern and SRS of India.

\begin{tabular}{|c|c|c|c|c|c|c|c|c|c|}
\hline Life Tables & Sex & $\begin{array}{c}\text { Linear relation } \\
\text { between } l_{1} \text { and } e_{1}\end{array}$ & $\mathrm{~N}$ & $\mathrm{R}^{2}$ & $\mathrm{SE}$ & $\begin{array}{l}\text { Quadratic relation } \\
\text { between } l_{1} \text { and } e_{0}\end{array}$ & $\mathrm{~N}$ & $\mathrm{R}^{2}$ & SE \\
\hline \multirow[t]{2}{*}{ West Model } & Male & $\begin{aligned} e_{1}=- & 40.346 \\
& +111.307 l_{1}\end{aligned}$ & 25 & 0.933 & 3.74 & $\begin{array}{c}e_{0}=84.967-257.510 l_{1} \\
+246.629 l_{1}^{2}\end{array}$ & 25 & 0.998 & 0.78 \\
\hline & Female & $\begin{aligned} e_{1}=- & 60.751 \\
& +135.066 l_{1}\end{aligned}$ & 25 & 0.968 & 2.70 & $\begin{array}{c}e_{0}=133.214-388.317 l_{1} \\
+334.049 l_{1}^{2}\end{array}$ & 25 & 0.998 & 0.81 \\
\hline \multirow[t]{2}{*}{$\begin{array}{l}\text { U.N. Model } \\
\text { (South Asian) }\end{array}$} & Male & $\begin{aligned} e_{1}=- & 77.720 \\
& +156.938 l_{1}\end{aligned}$ & 41 & 0.998 & 0.38 & $\begin{array}{c}e_{0}=72.919-243.711 l_{1} \\
+252.149 l_{1}^{2}\end{array}$ & 41 & 1.000 & 0.17 \\
\hline & Female & $\begin{aligned} e_{1}=- & 119.620 \\
& +203.758 l_{1}\end{aligned}$ & 41 & 1.000 & 0.05 & $\begin{aligned} e_{0}= & -2.147-113.232 l_{1} \\
& +200.471 l_{1}^{2}\end{aligned}$ & 41 & 1.000 & 0.05 \\
\hline \multirow[t]{3}{*}{ SRS (India) } & Male & $\begin{aligned} e_{1}=- & 69.986 \\
& +145.983 l_{1}\end{aligned}$ & 12 & 0.978 & 0.48 & $\begin{array}{c}e_{0}=15.008-100.361 l_{1} \\
+162.347 l_{1}^{2}\end{array}$ & 12 & 0.989 & 0.47 \\
\hline & Female & $\begin{aligned} e_{1}= & -79.992 \\
& +157.416 l_{1}\end{aligned}$ & 12 & 0.953 & 0.81 & $\begin{aligned} e_{0}= & -35.192 \\
& +113.168 l_{1}^{2}\end{aligned}$ & 12 & 0.975 & 0.75 \\
\hline & Person & $\begin{aligned} e_{1}= & -70.291 \\
& +146.344 l_{1}\end{aligned}$ & 12 & 0.982 & 0.79 & $\begin{array}{c}e_{0}=-16.071-31.722 l_{1} \\
+124.427 l_{1}^{2}\end{array}$ & 12 & 0.991 & 0.46 \\
\hline
\end{tabular}

N: Number of data points, SE: Standard error of the estimate. 
Sarma and Choudhury: A new model for estimating district life expectancy at birth in India (Assam state)

Table 2: Linear regression equation between $e_{1}$ and $l_{1}$ of the major states.

\begin{tabular}{llccc}
\hline State & $\begin{array}{c}\text { Linear regression equation } \\
\text { between } l_{1} \text { and } e_{1}\end{array}$ & $\mathrm{~N}$ & $\mathrm{R}^{2}$ & $\mathrm{SE}$ \\
\hline Andhra Pradesh & $e_{1}=-122.380+201.310 l_{1}$ & 12 & 0.90 & 1.31 \\
Assam & $e_{1}=-110.288+187.295 l_{1}$ & 12 & 0.96 & 0.71 \\
Bihar & $e_{1}=-62.003+134.44 l_{1}$ & 12 & 0.88 & 0.73 \\
Gujarat & $e_{1}=-49.819+123.899 l_{1}$ & 12 & 0.97 & 0.64 \\
Haryana & $e_{1}=-112.04+193.876 l_{1}$ & 12 & 0.83 & 1.24 \\
Himachal Pradesh & $e_{1}=-95.50+174.693 l_{1}$ & 12 & 0.89 & 1.23 \\
Karnataka & $e_{1}=-128.83+209.131 l_{1}$ & 12 & 0.63 & 1.81 \\
Kerala & $e_{1}=-117.388+193.181 l_{1}$ & 12 & 0.98 & 0.39 \\
Madhya Pradesh & $e_{1}=-73.883+151.959 l_{1}$ & 12 & 0.85 & 1.10 \\
Maharashtra & $e_{1}=-109.283+186.979 l_{1}$ & 12 & 0.95 & 0.77 \\
Orissa & $e_{1}=-25.346+97.223 l_{1}$ & 12 & 0.81 & 0.98 \\
Punjab & $e_{1}=-49.335+127.175 l_{1}$ & 12 & 0.88 & 0.91 \\
Rajasthan & $e_{1}=-122.85+206.293 l_{1}$ & 12 & 0.94 & 0.92 \\
Tamil Nadu & $e_{1}=-91.527+166.179 l_{1}$ & 12 & 0.98 & 0.61 \\
Uttar Pradesh & $e_{1}=-43.961+117.71 l_{1}$ & 12 & 0.96 & 0.95 \\
West Bengal & $e_{1}=-41.153+113.723 l_{1}$ & 12 & 0.80 & 0.69 \\
\hline
\end{tabular}

it will at least demote the problem of overlooking macro-level (state) disparity in $e_{0}$ to the micro (district) level. The estimating equations of $e_{0}$ for the major states are presented in Table 3.

Using the estimated values of $l_{1}$ for the districts and the estimating equation of the corresponding state, we can estimate the $e_{0}$ of the districts of that state.

Sarma and Choudhury (2012) have estimated $q(1)$ [hence $\left.l_{1}=1-q(1)\right]$ at the state level of India from CEB, CS data of the 2001 census by smoothing the child mortality estimates, obtained by the Brass method and using the Weibull survival function. They have established the reliability of the estimates by cross-checking the increase/decrease of the percentage of children dying between 1991 and 2001 with the increase/decrease of IMR between 1991 and 2001. We have used this procedure to estimate $q(1)$ (and hence $l_{1}$ ) for the districts of India for 1991 and 2001. The increase/decrease of $q(1)$ between 1991 and 2001 are compared with the increase/decrease of the percentage of children who died between 1991 and 2001 (reported by women in the childbearing age groups in 1991 and 2001 censuses) at the district level and found to be tallied with a Spearman's correlation coefficient of 0.98 . This establishes the reliability of the district level estimates of $l_{1}$. Using these estimated $l_{1}$ values of 2001, $e_{0}$ of the selected districts for 2001 were estimated by using the quadratic regression equation of the state to which the districts belong (Table 5).

The CEB, CS data of the 2011 census have not been published at the time of preparing this paper, and we could not estimate the district $l_{1}$ values for 2011 by the method suggested by Sarma and Choudhury (2012). However, the Office of the Registrar General of India published estimates of the infant mortality rates (IMR) of districts with maximum and minimum IMR for nine selected states in the bulletin of the Annual Health Survey (2010-11). Of these nine states, six states-viz., Rajasthan, Uttar Pradesh, Bihar, Orissa, Madhya Pradesh, and Assam-are major states. Converting these IMR to $q(1)$ (and hence to $l_{1}$ ), we have estimated the $e_{0}$ of these districts for 2010 using the estimating quadratic equations of the corresponding states (Refer to Table 3).

The SPSS 17.0 software was used for data analysis. 
Table 3. Estimating equations for life expectancy at birth of the major states of India.

\begin{tabular}{llccc}
\hline State & \multicolumn{1}{c}{ Regression equation } & $\mathrm{N}$ & $\mathrm{R}^{2}$ & $\mathrm{SE}$ \\
\hline Andhra Pradesh & $e_{0}=-55.591+135.095 l_{1}^{2}$ & 12 & 0.94 & 1.20 \\
Assam & $e_{0}=286.972-748.332 l_{1}+542.972 l_{1}^{2}$ & 12 & 0.96 & 0.81 \\
Bihar & $*_{e_{0}}=-113.130+185.717 l_{1}$ & 12 & 0.94 & 0.67 \\
Gujarat & $e_{0}=1.178-51.052 l_{1}+124.910 l_{1}^{2}$ & 12 & 0.99 & 0.61 \\
Haryana & $*_{e_{0}}=-161.111+242.501 l_{1}$ & 12 & 0.94 & 1.14 \\
Himachal Pradesh & $*_{e_{0}}=-146.658+225.741 l_{1}$ & 12 & 0.94 & 1.08 \\
Karnataka & $*_{0}=-180.078+260.332 l_{1}$ & 12 & 0.76 & 1.66 \\
Kerala & $e_{0}=-56.376+133.205 l_{1}^{2}$ & 12 & 0.99 & 0.37 \\
Madhya Pradesh & $*_{e_{0}}=-117.200+194.123 l_{1}$ & 12 & 0.93 & 0.94 \\
Maharashtra & $*_{e_{0}}=-160.418+238.181 l_{1}$ & 12 & 0.98 & 0.70 \\
Orissa & $e_{0}=-1353.414+3014.187 l_{1}-1607.363 l_{1}^{2}$ & 12 & 0.97 & 0.60 \\
Punjab & $e_{0}=-21.974+100.664 l_{1}^{2}$ & 12 & 0.95 & 0.86 \\
Rajasthan & $e_{0}=-53.878+137.479 l_{1}^{2}$ & 12 & 0.96 & 0.86 \\
Tamil Nadu & $*_{e_{0}}=-140.723+215.470 l_{1}$ & 12 & 0.99 & 0.55 \\
Uttar Pradesh & $e_{0}=-252.46+538.328 l_{1}-216.23 l_{1}^{2}$ & 12 & 0.98 & 0.77 \\
West Bengal & $*_{e_{0}}=-98.483+171.536 l_{1}$ & 12 & 0.92 & 0.69 \\
\hline
\end{tabular}

*Tolerance limit for entering variables $(=0.0001)$ is reached.

\section{Results and discussion}

We have estimated the $e_{0}$ of the major states from the estimating equations of the states (refer to Table 3) using the SRS $q(1)$ of these states for 2001-05. The estimates are compared with the SRS $e_{0}$ of the same period and found to be satisfactory, having a mean 0.61 of the absolute differences (Table 4).

It has been found (from Table 5) that the districts Kota in Rajasthan and Kanpur Nagar in Uttar Pradesh achieved a remarkable reduction in $q(1)$, from 0.073 to 0.035 and 0.091 to 0.035 , respectively, and also gained in $e_{0}$, from 64.3 to 74.1 and 58.2 to 65.7, respectively, during the period 2001-2010. The districts Patna in Bihar, Dhemaji in Assam, Baleshwar in Orissa, and Indore in Madhya Pradesh have achieved considerable reduction in $q(1)$ and considerable gain in $e_{0}$.

Among the districts with maximum IMR, Jalor in Rajasthan and Panna in Madhya Pradesh achieved considerable reduction in $q(1)$ and a moderate gain in $e_{0}$ during 2001-2010, while Shrawasti in Uttar Pradesh, Kokrajhar in Assam, and Madhepura in Bihar experienced marginal declines in $q(1)$ and marginal increases in $e_{0}$ during 2001-2010, while Balangir in Orissa stands as an exception, with increased $q(1)$ and decreased $e_{0}$ this time.

Table 6 presents the estimated $q(1)$ and $e_{0}$ for the districts of Assam for 2001 and 2010. Note that Dibrugarh district, where $q(1)$ was least and $e_{0}$ was highest in 2001, experienced an increase in $q(1)$ and decrease in $e_{0}$ in 2010. Tinsukia ranked second in terms of $e_{0}$ in 2001 and remained almost constant both in $q(1)$ and $e_{0}$ in 2010. Golaghat and Jorhat were ranked third in terms of $e_{0}$ in 2001, but experienced marginal gain in $e_{0}$ and moderate decline in $q(1)$ in 2010, with Jorhat being the better performer. Other districts that had been comparatively better off in terms of $e_{0}$ in 2001 experienced a moderate reduction in $q(1)$ and a moderate gain in $e_{0}$ in 2010: the districts of Dhemaji, Goalpara, 
Sarma and Choudhury: A new model for estimating district life expectancy at birth in India (Assam state)

Table 4. SRS $e_{0}(2001-05)$ and Estimated $e_{0}(2001)$ of the major states of India using the regression equations.

\begin{tabular}{|c|c|c|c|c|c|c|}
\hline \multirow{2}{*}{ State } & \multirow{2}{*}{$\begin{array}{l}\text { SRS q(1) } \\
(2001-05)\end{array}$} & \multirow{2}{*}{$\begin{array}{c}\text { Estimated } \\
e_{0}(2001)\end{array}$} & \multirow{2}{*}{$\begin{array}{c}\mathrm{SRS} e_{0} \\
(2001-05)\end{array}$} & \multirow{2}{*}{$\begin{array}{l}\text { Absolute } \\
\text { difference }\end{array}$} & \multicolumn{2}{|c|}{$\begin{array}{c}95 \% \text { prediction } \\
\text { interval }\end{array}$} \\
\hline & & & & & LICB & UICB \\
\hline Andhra Pradesh & 0.06290 & 63.04 & 64.10 & 1.06 & 60.20 & 65.85 \\
\hline Assam & 0.07981 & 58.13 & 58.70 & 0.57 & 56.02 & 60.04 \\
\hline Bihar & 0.06099 & 61.26 & 61.40 & 0.14 & 59.67 & 62.85 \\
\hline Gujarat & 0.06143 & 63.30 & 63.90 & 0.60 & 61.78 & 64.82 \\
\hline Haryana & 0.06953 & 64.53 & 65.90 & 1.37 & 61.85 & 67.21 \\
\hline Himachal Pradesh & 0.05081 & 67.61 & 66.80 & 0.81 & 64.98 & 70.25 \\
\hline Karnataka & 0.05870 & 64.97 & 65.10 & 0.13 & 60.94 & 69.01 \\
\hline Kerala & 0.01169 & 73.73 & 73.90 & 0.17 & 72.85 & 74.61 \\
\hline Madhya Pradesh & 0.09297 & 58.88 & 57.70 & 1.18 & 56.50 & 61.25 \\
\hline Maharashtra & 0.04178 & 67.81 & 66.90 & 0.91 & 66.11 & 69.51 \\
\hline Orissa & 0.08140 & 59.08 & 59.20 & 0.12 & 57.56 & 60.61 \\
\hline Punjab & 0.05240 & 68.42 & 69.20 & 0.78 & 66.38 & 70.45 \\
\hline Rajasthan & 0.08423 & 61.42 & 61.70 & 0.28 & 59.36 & 63.48 \\
\hline Tamil Nadu & 0.04250 & 65.59 & 66.00 & 0.41 & 64.28 & 66.90 \\
\hline Uttar Pradesh & 0.08627 & 58.90 & 59.80 & 0.90 & 56.98 & 60.91 \\
\hline West Bengal & 0.04735 & 64.93 & 64.60 & 0.33 & 63.36 & 66.49 \\
\hline
\end{tabular}

LICB: Lower Individual Confidence Bound, UICB: Upper Individual Confidence Bound

Bongaigaon, Barpeta, and Hailakandi, which had a high $q(1)$ and low $e_{0}$ in 2001, showed excellent performance in reducing $q(1)$ and gaining in $e_{0}$ in 2010, with Dhemaji district having lowest $q(1)$ and highest $e_{0}$. Dhubri district, which had lowest $e_{0}$ in 2001, managed to lower its $q(1)$ and gained considerably in $e_{0}$, but still placed only just above Kokrajhar and equal with Marigaon in terms of $q(1)$ and $e_{0}$ in 2010. The districts Kokrajhar, Marigaon, Nagaon, and Sonitpur, which had comparatively moderate $e_{0}$ in 2001, only managed to reduce $q(1)$ and gain in $e_{0}$ marginally in 2010.

Table 5: Estimated $e_{0}$ of the districts $(2001,2010)$ with minimum and maximum IMR estimated by AHS (2010).

\begin{tabular}{|c|c|c|c|c|c|c|c|c|c|}
\hline & \multicolumn{4}{|c|}{ District with minimum IMR } & \multicolumn{5}{|c|}{ District with maximum IMR } \\
\hline $\begin{array}{c}\text { State / } \\
\text { District }\end{array}$ & $\begin{array}{c}q(1) \\
(2001) \\
\end{array}$ & $\begin{array}{c}e_{0} \\
(2001)\end{array}$ & $\begin{array}{c}q(1) \\
(2010) \\
\end{array}$ & $\begin{array}{c}e_{0} \\
(2010)\end{array}$ & District & $\begin{array}{c}q(1) \\
(2001)\end{array}$ & $\begin{array}{c}e_{0} \\
(2001) \\
\end{array}$ & $\begin{array}{c}q(1) \\
(2010)\end{array}$ & $\begin{array}{c}e_{0} \\
(2010)\end{array}$ \\
\hline $\begin{array}{l}\text { Rajasthan / } \\
\text { Kota } \\
\text { Uttar Pradesh / }\end{array}$ & 0.073 & 62.3 & 0.035 & 74.1 & Jalor & 0.094 & 59.0 & 0.076 & 63.5 \\
\hline $\begin{array}{l}\text { Kanpur Nagar } \\
\text { Bihar / }\end{array}$ & 0.091 & 58.2 & 0.035 & 65.7 & Shrawasti & 0.108 & 55.7 & 0.098 & 57.2 \\
\hline $\begin{array}{l}\text { Patna } \\
\text { Assam / }\end{array}$ & 0.064 & 60.7 & 0.038 & 65.5 & Madhepura & 0.069 & 59.8 & 0.069 & 59.8 \\
\hline $\begin{array}{l}\text { Dhemaji } \\
\text { Orissa / }\end{array}$ & 0.066 & 61.7 & 0.043 & 68.1 & Kokrajhar & 0.079 & 61.6 & 0.073 & 59.9 \\
\hline $\begin{array}{l}\text { Baleshwar } \\
\text { Madhya Pradesh / }\end{array}$ & 0.082 & 59.0 & 0.048 & 59.3 & Balangir & 0.084 & 58.9 & 0.095 & 57.9 \\
\hline Indore & 0.055 & 66.2 & 0.039 & 69.3 & Panna & 0.133 & 51.1 & 0.089 & 59.6 \\
\hline
\end{tabular}


Table 6. Estimated $q(1)$ and $e_{0}$ for 2001 and 2010 for the districts of Assam.

\begin{tabular}{|c|c|c|c|c|c|c|c|c|}
\hline \multirow{3}{*}{ State/District } & \multicolumn{4}{|c|}{2001} & \multicolumn{4}{|c|}{2010} \\
\hline & \multirow{2}{*}{$q(1)$} & \multirow{2}{*}{$e_{0}$} & \multicolumn{2}{|c|}{$\begin{array}{c}95 \% \text { prediction } \\
\text { interval }\end{array}$} & \multirow[t]{2}{*}{$q(1)$} & \multirow{2}{*}{$e_{0}$} & \multicolumn{2}{|c|}{$\begin{array}{c}95 \% \text { prediction } \\
\text { interval }\end{array}$} \\
\hline & & & LICI & UICI & & & LICB & UICB \\
\hline Kokrajhar & 0.079 & 58.5 & 56.2 & 60.3 & 0.071 & 60.8 & 57.9 & 62.7 \\
\hline Dhubri & 0.101 & 52.9 & 51.0 & 55.0 & 0.067 & 61.8 & 58.6 & 64.1 \\
\hline Goalpara & 0.089 & 55.9 & 53.9 & 57.7 & 0.053 & 66.1 & 60.7 & 69.6 \\
\hline Bongaigaon & 0.085 & 56.9 & 54.8 & 58.7 & 0.050 & 67.0 & 61.1 & 70.9 \\
\hline Barpeta & 0.083 & 57.4 & 55.3 & 59.2 & 0.046 & 68.4 & 61.6 & 72.7 \\
\hline Kamrup & 0.066 & 62.2 & 58.8 & 64.4 & 0.044 & 69.0 & 61.8 & 73.6 \\
\hline Nalbari & 0.071 & 60.7 & 57.9 & 62.7 & 0.060 & 63.9 & 59.8 & 66.7 \\
\hline Darrang & 0.097 & 53.9 & 51.9 & 55.8 & 0.065 & 62.6 & 59.0 & 64.8 \\
\hline Marigaon & 0.083 & 57.4 & 55.3 & 59.2 & 0.067 & 61.8 & 58.6 & 64.1 \\
\hline Nagaon & 0.081 & 57.9 & 55.8 & 59.7 & 0.062 & 63.4 & 59.5 & 65.9 \\
\hline Sonitpur & 0.077 & 59.0 & 56.6 & 60.8 & 0.064 & 62.8 & 59.1 & 65.1 \\
\hline Lakhimpur & 0.068 & 61.6 & 58.4 & 63.7 & 0.053 & 66.1 & 60.7 & 69.6 \\
\hline Dhemaji & 0.066 & 62.2 & 58.8 & 64.4 & 0.042 & 69.6 & 62.0 & 74.6 \\
\hline Tinsukia & 0.053 & 66.1 & 60.7 & 69.6 & 0.052 & 66.4 & 60.9 & 70.0 \\
\hline Dibrugarh & 0.046 & 68.4 & 61.6 & 72.7 & 0.052 & 66.4 & 60.9 & 70.0 \\
\hline Sibsagar & 0.069 & 61.3 & 58.3 & 63.4 & 0.055 & 65.5 & 60.5 & 68.7 \\
\hline Jorhat & 0.060 & 64.0 & 59.8 & 66.7 & 0.054 & 65.8 & 60.6 & 69.1 \\
\hline Golaghat & 0.060 & 64.0 & 59.8 & 66.7 & 0.058 & 64.4 & 60.1 & 67.5 \\
\hline KarbiAnglong & 0.084 & 57.2 & 55.1 & 58.9 & 0.056 & 65.3 & 60.3 & 68.3 \\
\hline North Cachar Hills & 0.073 & 60.1 & 57.5 & 62.0 & 0.055 & 65.5 & 60.5 & 68.7 \\
\hline Cachar & 0.084 & 57.2 & 55.1 & 58.9 & 0.054 & 65.8 & 60.6 & 69.1 \\
\hline Karimganj & 0.093 & 54.9 & 52.9 & 56.8 & 0.065 & 62.6 & 59.0 & 64.8 \\
\hline Hailakandi & 0.084 & 57.2 & 55.1 & 58.9 & 0.052 & 66.4 & 60.9 & 70.0 \\
\hline
\end{tabular}

LICB: Lower Individual Confidence Bound, UICB: Upper Individual Confidence Bound.

We could not compare our district estimates of $e_{0}$, due to the absence of $e_{0}$ estimates at the district level in India from any reliable source. However, we have provided an ex-post-facto test at the state level that demonstrates the method is capable of providing considerably accurate estimates of life expectancy at birth (Table 4). It is obvious from the estimating equations that the accuracy of the estimate of life expectancy at birth is sensitive to the estimate of probability of surviving to age one $\left(l_{1}\right)$. As the CEB, CS data of the 2011 census have not been released yet, we could not estimate the $l_{1}$ values for the districts for 2011 by the method suggested by Sarma and Choudhury (2012), and had to depend on the IMR estimates of AHS, 2010-11 to estimate $l_{1}$. Thus the accuracy of the district estimates of life expectancy at birth for 2010 are subject to the accuracy of the IMR estimates of AHS, 2010-11.

In conclusion, we would like to state that in the face of scarcity of data at the district level for India, this paper provides a new way to estimate life expectancy at birth from limited data that has (1) implications beyond the districts in India; and (2) shows the value of the method by estimating life expectancy at birth for small areas such as districts. These results have implications for further research in the assessment of disparities in life expectancy across districts of India, along the line of county-specific studies in the United States (Ezzati et al. 2008; Kulkarni et al. 2011). The relationship between life expectancy at birth and socio-economic status (SES) have implications for the study of 
Sarma and Choudhury: A new model for estimating district life expectancy at birth in India (Assam state)

social inequality and its relationship to health outcomes (Swanson et al. 2009). Availability of district life expectancy estimates may open up further research in social inequality across districts in India.

\section{References}

Arriaga, E.E. 1968. New Life Tables for Latin American Population in the Nineteenth and Twentieth Centuries. Population Monographs Series 3. Berkeley: University of California.

Bhalotra, S. 2007. Spending to save? State health expenditure and infant mortality in India. Discussion Paper No. 2914, July, University of Bristol, CMPO and IZA, Bonn, Germany. http://ftp.iza.org/ dp2914.pdf (retrieved April 5, 2012).

Bhat, P.N.M. 1987. Mortality in India: Levels, trends and patterns. PhD Diss. University of Pennsylvania, Philadelphia.

Brass, W. 1964. Uses of census or survey data for the estimation of vital rates. Paper presented for the African Seminar on Vital Statistics. Addis Ababa (December14-19).

- 1975. Methods of Estimating Fertility and Mortality from Defective and Limited Data. Occasional Publications of the Laboratory. Chapel Hill: Laboratory for Population Statistics, University of North Carolina.

Carrier, N.H., and J. Hobcraft. 1971. Demographic Estimation for Developing Societies: A Manual of Techniques for the Detection and Reduction of Errors in Demographic Data. London (UK): London School of Economics, Population Investigation Committee.

Coale, A.J., and P. Demeney. 1966. Regional Model Life Tables and Stable Populations. Princeton NJ: Princeton University Press.

- 1983. Regional Model Life Tables and Stable Populations. 2nd edn. New York: Academic Press.

Das, A. 1999. Socio-economic development in India: A regional analysis. Development and Society 28(2):313-345.

Ezzati, M., A. Friedman, S. Kulkarni, and C. Murray. 2008. The reversal of fortunes: Trends in county and cross-county mortality disparities in the United States. PLoS Medicine 5(4):1-12.

Feinlieb, M. 1984. Technical Assistance and the Data Use Conference on Small Area Statistics, 1-2. Invited Papers to the Data Use Conference On Small Area Statistics, National Center For Health Statistics, Washington DC, US Dept. of Health and Human Services.

Gunasekaran, S., J.A. Palmore, and R.W. Gardner. 1981. Regression estimates of mortality from incomplete death registration. Asian and Pacific Census Forum 7:5-9.

Hill, K. 1977. Estimating adult mortality levels from information on widowhood. Population Studies 31(1):75-84.

Hill, K., and J. Trussell. 1977. Further developments in indirect mortality estimation. Population Studies 31(2):313-334.

Kulkarni, S., A. Levin-Rector, M. Ezzati, and C. Murray. 2011. Falling behind: Life expectancy in US counties from 2000 to 2007 in an International Context. Population Health Metrics 9:16. http:/ /www. pophealthmetrics.com/content/9/1/16. (retrieved August 15, 2013) 
Maccann, J.C. 1976. A technique for estimating life expectancy with crude vital rates. Demography 13:259_ 272.

Mahapatra, P. 2010. An overview of the SRS in India. Paper presented at the Prince Mahidol Award Conference \& Global Health Information Forum, Bangkok (Jan27-30). http:/ /www.ihsnet.org.in/ SampleRegistrationSysteminIndia.htm. (retrieved August 15, 2013)

Malaker, C.R. 1986. Estimation of adult mortality in India: 1971-81. Demography India 15(1):126-135.

Malaker, C.R., and N.R. Crook. 1989. The use of widowhood data for investigation of mortality differentials in West Bengal: A district-level analysis. Demography India 18(1\&2):121-129.

Mazur, D.P. 1969a. Expectancy of life at birth in 36 nationalities of the Soviet Union: 1958-60. Population Studies 23:225-246.

1969b. Techniques for estimating basic demographic measures from limited data for the U.S.S.R.: 1959-60. Duplicated. London: International Union for the Scientific Study of Population.

1972. Using regression models to estimate the expectation of life for the U.S.S.R. Journal of the American Statistical Association 67:31-36.

Pathak, K.B., and B.S. Singh. 1992. A method for estimating expectation of life at birth at sub-national level. Demography India 21(2):267-276.

Pathak, K.B., F. Ram, and B.S. Singh. 1988. A new method of estimating infant and child mortality from data on children ever born and children surviving. Janasamkbya 6(2):159-68.

Preston, S.H., and N.G. Bennett. 1983. A census-based method for estimating adult mortality. Population Studies 37(1):91-104.

Preston, S.H., P. Heuveline, and M. Guillot. 2003. Demography: Measuring and Modeling Population Processes. First Indian Reprint edn. London (UK): Blackwell Publishers Limited.

Registrar General of India.1970-75, 1976-80, 1986-90, 1987-91, 1989-93, 1990-94, 1991-95, 199296, 1993-97, 1996-00, 1997-01, 2000-04, 2001-05. SRS-based Abridged Life Tables of India and the Major States. New Delhi: Registrar General of India.

. 2011. Annual Health Survey Bulletin 2010-11. New Delhi: Ministry of Home Affairs.

Romo, V.C., and S. Becker. 2011. The crossover between life expectancies at birth and at age one: The imbalance in the life table. Demographic Research 24:113-144.

Sarma, R., and L. Choudhury. 2012. A critique of infant mortality estimates in India. Journal of Data Science 10:563-578.

Shryock, H.S., and J.S. Seigel. 1976. The life table, in Methods and Materials of Demography. New York: Academic Press, pp: 249-271.

Siler, W. 1979. A competing risk model for animal mortality. Ecology 60:750-757.

Sullivan, J.M. 1972. Models for the estimation of probability of dying between birth and exact ages of early childhood. Population Studies 26(1):79-97.

Swanson, D.A. 1989. A state-based regression model for estimating sub-state life expectancy. Demography 26(1):161-170.

Swanson, D.A., and J.A. Palmore. 1976. Two-parameter regression estimates of current life expectancy at birth: Part I. Asian and Pacific Census Forum 3:5-10. 
Sarma and Choudhury: A new model for estimating district life expectancy at birth in India (Assam state)

Swanson, D.A., and E.G. Stockwell. 1986. Geographic variation of longevity in Ohio, 1930 and 1980. Obio Journal of Science 869(September):144-149.

Swanson, D.A., M. McGehee, and N. Hoque. 2009. Socio-economic status and life expectancy in the United States, 1970-1990. Population Review 48(1):39-63.

Swanson, D.A., J.A. Palmore, and C. Sundaram. 1977. Two-parameter regression estimates of current life expectancy at birth: Part II. Asian and Pacific Census Forum 3(May):5-10.

Trussell, T.J. 1975. A re-estimation of the multiplying factors for the Brass Technique for determining childhood survivorship rates. Population Studies 29 (1): 97-108.

United Nations. 1982. Model Life Tables for Developing Countries. Population Studies 77. New York: United Nations.

1983. Indirect Techniques for Demographic Estimation, Manual X. Population Studies 81, New York: United Nations Department of International Economic, Social Affairs, and Population Studies.

Wennberg, J., and A. Gittelsohn. 1975. Small area variations in health care delivery. Science 182:11021108.

1980. A Small Area Approach to the Analysis of Health System Performance. Health Planning Methods and Technology Series 21. Washington DC: Bureau of Health Planning, Public Health Service, US Department of Health and Social Services. 